\title{
Evaluation of the THRESHOLD trainer for inspiratory cle endurance training: comparison with weighted plunger method
}

\section{mus- the}

\author{
P.H. Johnson, A.J. Cowley, W.J.M. Kinnear
}

\begin{abstract}
Evaluation of the THRESHOLD® trainer for inspiratory muscle endurance training: comparison with the weighted plunger method. P.H. Johnson, A.J. Cowley, W.J.M. Kinnear. (C)RS Journals Ltd 1996.

ABSTRACT: Inspiratory muscle training (IMT) has been shown to enhance exercise performance. The weighted plunger (WP) system of inspiratory threshold loading is the most commonly used method of IMT, but is expensive and cumbersome. We have evaluated a commercially available portable spring-loaded IMT device, the THRESHOLD® trainer.

The WP and THRESHOLD® trainer devices were evaluated with their opening pressures set, in random order, at 10, 20,30 and $40 \mathrm{cmH}_{2} \mathrm{O}$. Using an airpump, pressure at the valve inlet was recorded at the point at which the valve opened, and at airflow rates of $20,40,60,80$ and $100 \mathrm{~L} \cdot \mathrm{min}^{-1}$. Ten THRESHOLD $®$ trainers were then compared using the same opening pressures and airflow rates. Finally, 10 patients with stable chronic heart failure (CHF) inspired, in random order, through the WP and THRESHOLD $®$ trainer for $4 \mathrm{~min}$ each. The pressuretime product (PTP) was calculated for each $4 \mathrm{~min}$ period, to compare the work performed on inspiring through each device.

The mean measured opening pressures for the WP set at 10, 20, 30 and 40 $\mathrm{cmH}_{2} \mathrm{O}$, were 9.0, 19.3, 27.9 and $39.2 \mathrm{cmH}_{2} \mathrm{O}$, respectively, and there was little change over the range of flow tested. Corresponding values for the THRESHOLD ${ }^{\circledR}$ trainer were 7.5, 16.9, 26.2 and $39.1 \mathrm{cmH}_{2} \mathrm{O}$, with the pressure being closer to the set pressure as flow increased to that seen in clinical practice. The 10 different trainers tested performed very similarly to one another. Work performed (as measured by PTP) on inspiring through the WP and THRESHOLD ${ }^{\circledR}$ trainer was not significantly different.

Although less accurate than the weighted plunger, the THRESHOLD $®$ trainer is an inexpensive device of consistent quality. In a clinical setting it would be a satisfactory option for inspiratory muscle training in most patients, but less so in patients with very low inspiratory flow rates.

Eur Respir J., 1996, 9, 2681-2684.
\end{abstract}

University Hospital, Nottingham, UK.

Correspondence: W.J.M. Kinnear

Dept of Respiratory Medicine

University Hospital

Nottingham NG7 2UH

UK

Keywords: Respiratory muscles threshold loading

training

weighted plunger

Received: June 241996

accepted after revision September 161996
Inspiratory muscle strength and endurance have been shown to be reduced in a number of conditions, such as chronic obstructive pulmonary disease (COPD) and chronic heart failure (CHF) $[1,2]$. Recently, much interest has been focused on the value of inspiratory muscle endurance training as a therapeutic option in such conditions [3]. A number of methods have been described, which can be used both to measure inspiratory muscle endurance (IME) and to train inspiratory muscles. The most commonly used method is inspiratory threshold loading, first described by NiCKERSON and KEENS [4], in which a weighted plunger is used, requiring the subject to generate and sustain a set inspiratory pressure in order to achieve airflow. Alternative methods described include voluntary isocapnic hyperpnoea, in which subjects hyperventilate at normocapnoea to a target minute ventilation [5], and another form of threshold loading using a solenoid device [6]. In this last technique, the subject has to generate a set pressure in order to initiate airflow, but the resistance is removed once airflow begins. The last two methods both require cumbersome and expensive equipment, and can generally only be used in a laboratory setting. The THRESHOLD® trainer is, however, a commercially available portable valve device, which utilizes the principle described by NICKERSON and KeENs [4] and is designed for IMT. The device is small and can be used at home with ease. We have evaluated the THRESHOLD® inspiratory muscle trainer and compared it with a weighted plunger (WP) constructed in our own workshops.

\section{Methods}

In our workshops, we constructed a pressure threshold valve based on the weighted plunger principle [4]. The plunger of this valve produced a seal using a rubber ring of " $\mathrm{V}$ " cross-section, in an attempt to emulate 


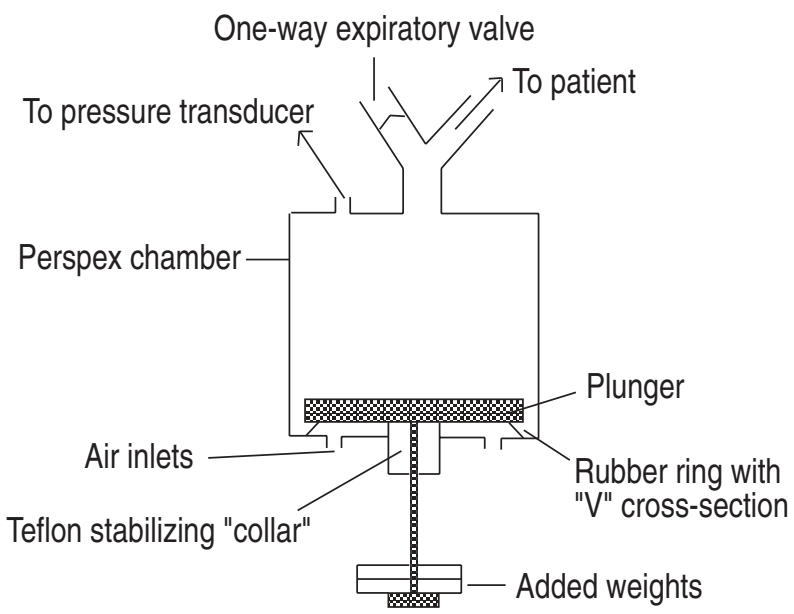

Fig. 1. - Diagram of the weighted plunger.

the refinement described by EASTwOod and HiLlman [7] of the original plunger design. Weights are added to the plunger to increase the threshold opening pressure, the increase in pressure depending upon the size of the plunger. For our device, increments of $270 \mathrm{~g}$ increased the threshold opening pressure by $10 \mathrm{cmH}_{2} \mathrm{O}$ each. The device is illustrated in figure 1.

This valve was compared with the THRESHOLD® inspiratory muscle trainer (Healthscan Products Inc., Cedar Grove, NJ, USA), which is a spring-loaded valve, the threshold opening pressure of which can be adjusted up or down by compressing or decompressing the spring, respectively. The device has a scale of threshold opening pressure printed on its side, allowing the opening pressure to be set according to these markings. The THRESHOLD® device is illustrated in figure 2.

The behaviour of both the weighted plunger and the THRESHOLD® trainer was assessed with the opening pressure set in increments of $10 \mathrm{cmH}_{2} \mathrm{O}$ from $10-40$ $\mathrm{cmH}_{2} \mathrm{O}$ inclusive. Two hundred and seventy gram weights were added to the plunger to set the opening pressures, and the THRESHOLD ${ }^{\circledR}$ trainer opening pressure was set according to the manufacturers markings. Using an air pump (KDG 2000; KDG flowmeters, Glasgow, UK), flow through each valve was increased in increments of $20 \mathrm{~L} \cdot \mathrm{min}^{-1}$ from 0 to $100 \mathrm{~L} \cdot \mathrm{min}^{-1}$, at each set opening pressure. A pneumotachograph head was attached to the opening of each of the two valves, and the pressure differential across the pneumotachograph and the pressure at the valve opening were measured (SiPlan Electronics Research). For each set opening pressure, the observed opening pressure was documented. This was defined as the pressure just before airflow commenced. The pressure was also documented at airflows of $20,40,60,80$

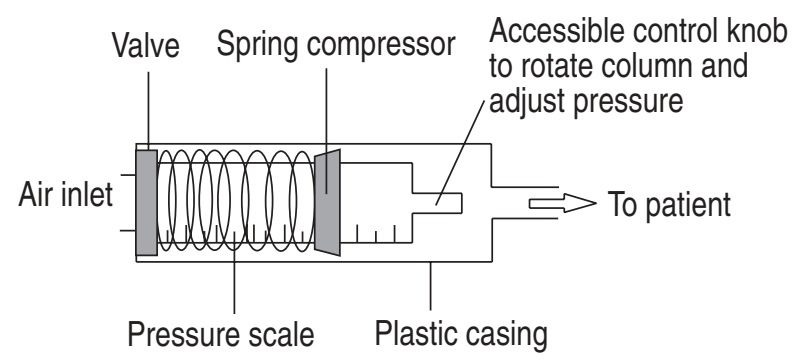

Fig. 2. - Diagram of the THRESHOLD® trainer and $100 \mathrm{~L} \cdot \mathrm{min}^{-1}$. Five sets of observations were made for each device, with the opening pressures from 10 to $40 \mathrm{cmH}_{2} \mathrm{O}$ performed in a different random order for each set of observations.

Ten different THRESHOLD® trainers were then compared with one another. For each trainer, the opening pressure was set in increments of $10 \mathrm{cmH}_{2} \mathrm{O}$ from 10 to $40 \mathrm{cmH}_{2} \mathrm{O}$, and the same method was used to increase airflow through the trainer from 0 to $100 \mathrm{~L} \cdot \mathrm{min}^{-1}$ in increments of $20 \mathrm{~L} \cdot \mathrm{min}^{-1}$. One set of observations was performed for each trainer, and the opening pressure observed was documented, together with the pressure at airflows of 20,40,60, 80 and $100 \mathrm{~L} \cdot \mathrm{min}^{-1}$.

Finally, 10 patients with stable CHF inspired for 4 min both through the WP and the THRESHOLD® trainer in random order. The pressure signal was passed through an analogue-to-digital converter (SiPlan Electronics Research, Stratford-upon-Avon, UK) to an A310 Microcomputer (Acorn) sampling at $100 \mathrm{~Hz}$. For each $4 \mathrm{~min}$ period, the total work performed by the patient was calculated as the pressure-time product (PTP). A noninvasive method of measuring PTP has been validated previously [8]. From the pressure signal, respiratory rate and duty cycle were calculated. The maximum inspiratory mouth pressure (MIP) for each patient was also measured: subjects were seated wearing a noseclip, and repeated maximal inspiratory manoeuvres were performed at functional residual capacity until two maximal values within $10 \%$ of one another were obtained. (P.K. Morgan, Chatham, Kent, UK). The highest recorded value was taken as the MIP.

Statistical comparisons were made using nonparametric tests in the FASTAT software package (SYSTAT Inc., Evanston, Illinois, USA)

\section{Results}

The THRESHOLD ${ }^{\circledR}$ valve opens at pressures several centimetres of water below the intended opening

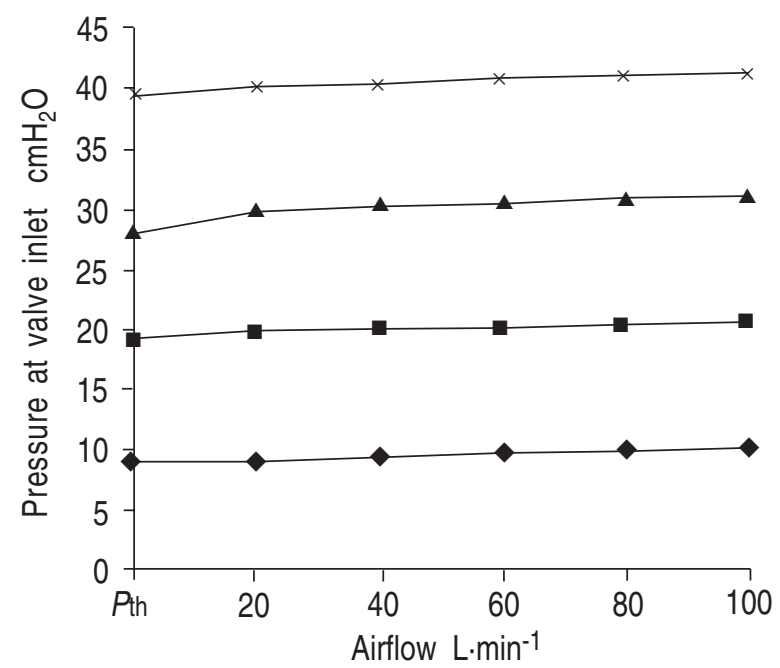

Fig. 3. - Pressure recorded at the valve inlet for the weighted plunger. The pressure values are shown for airflow rates of $0,20,40,60,80$ and $100 \mathrm{~L} \cdot \mathrm{min}^{-1}$, at set valve opening pressures of $10(-\bullet), 20$

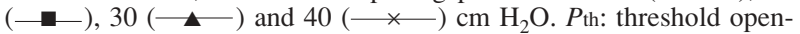
ing pressure. 


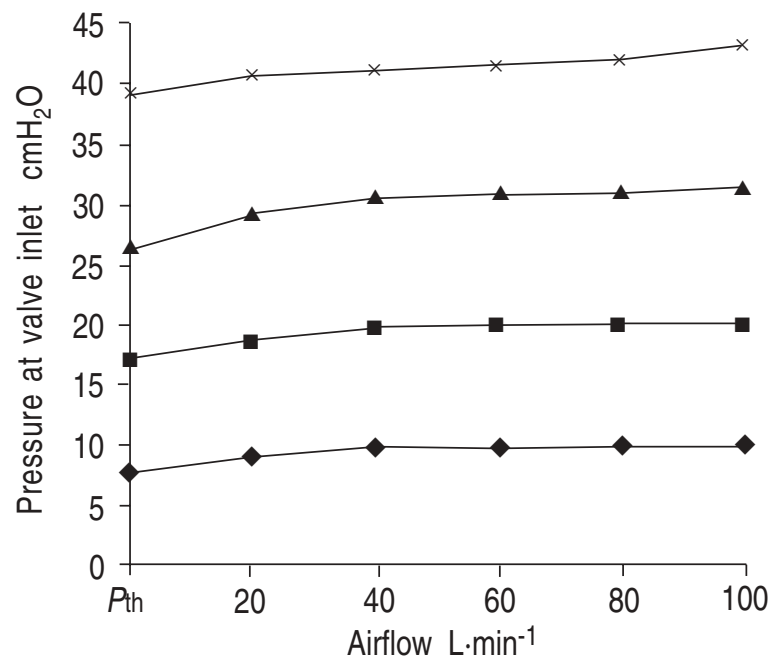

Fig. 4. - Pressure recorded at the valve inlet for one THRESHOLD® trainer. The pressure values are shown for airflow rates of $0,20,40$, 60,80 and $100 \mathrm{~L} \cdot \mathrm{min}^{-1}$, at set valve opening pressures of $10(-\downarrow)$, $20(-), 30(-)$ and $40(-x) \mathrm{cmH}_{2} \mathrm{O}$. P th: threshold opening pressure.

pressure, and at low flow rates the pressure remains below the set pressure. A plateau is then achieved above airflow rates of about $20 \mathrm{~L} \cdot \mathrm{min}^{-1}$, where pressure becomes more independent of flow and more accurately reflects the set pressure. At high pressures and high flow rates, the measured opening pressure across the trainer valve exceeds the set value by up to $5 \mathrm{cmH}_{2} \mathrm{O}$. The plunger behaved in a more consistent fashion, with much less deviation from the set opening pressures and very little variation in pressure with airflow. The pressure-flow characteristics of the weighted plunger and the THRESH$\mathrm{OLD}{ }^{\circledR}$ trainer at the different set opening pressures are shown in figures 3 and 4, respectively. Table 1 shows the mean (SD) values for the 10 different THRESHOLD ${ }^{\circledR}$ trainers.

For the 10 patients studied, the mean (SD) MIP was 72 (21) $\mathrm{cmH}_{2} \mathrm{O}$. Figure 5 shows the PTP for each patient breathing on the WP plotted against the PTP for the THRESHOLD ${ }^{\circledR}$ valve. For each patient, there was very little difference in PTP when breathing through the WP and THRESHOLD® valve. There was also no difference in mean duty cycle or respiratory rate, which were calculated for the 10 patients on each device as follows: mean (SD) duty cycle for the WP was $0.54(0.06)$ and for the THRESHOLD ${ }^{\circledR}$ valve $0.51(0.07)$. The mean (SD) respiratory frequency on the WP was 15.7 (3.8) breaths. $\mathrm{min}^{-1}$ and for the THRESHOLD ${ }^{\circledR}$ valve 17.2 (4.5) breaths $\cdot \mathrm{min}^{-1}$.

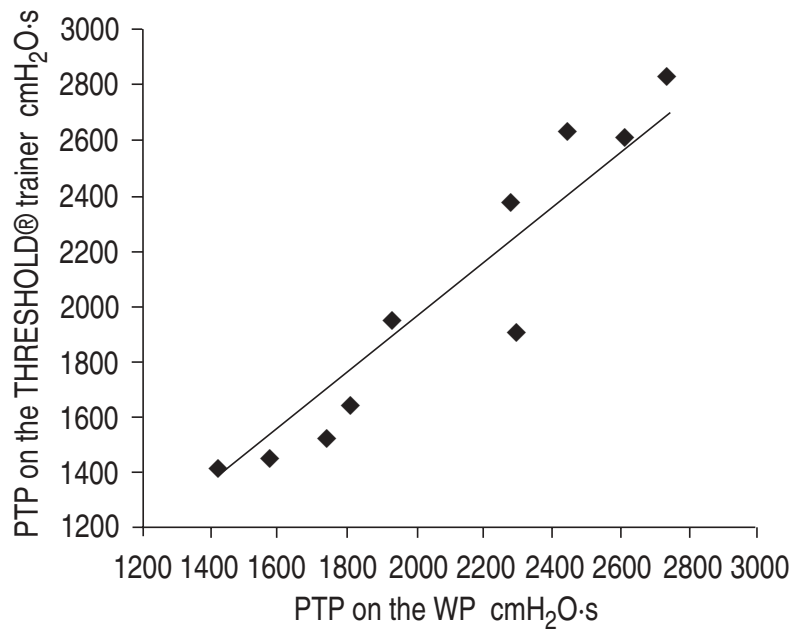

Fig. 5. - Work performed, expressed as pressure-time product (PTP) in $\mathrm{cmH}_{2} \mathrm{O} \cdot \mathrm{s}^{-1}$ seconds for 10 patients with stable chronic heart failure (CHF), breathing for $4 \mathrm{~min}$ through the weighted plunger (WP), plotted against the PTP for 4 min breathing through the THRESHOLD® trainer Line: line of identity.

\section{Discussion}

Mean inspiratory flow rates for normal subjects during inspiratory threshold loading are about $60 \mathrm{~L} \cdot \mathrm{min}^{-1}$ $[9,10]$. The fall in opening pressure below the set value at low flow rates with the THRESHOLD ${ }^{\circledR}$ trainer is, therefore, unlikely to be of relevance when training normal subjects. However, inspiratory flow rates in patients with lung disease may be lower, particularly if different breathing strategies are adopted. In patients with COPD, mean inspiratory flow rates of $25 \mathrm{~L} \cdot \mathrm{min}^{-1}$ have been documented during inspiratory muscle endurance testing [11]. At these flow rates, the work performed by the inspiratory muscles could, in theory, be considerably less with the THRESHOLD® device than with the weighted plunger. Patients might adjust their breathing pattern to prolong inspiratory time, hence reducing inspiratory flow rates. Our data for patients with CHF suggests that the work performed with the two devices is similar.

At higher flow rates, the opening pressure is well sustained, but our experience shows that using the manufacturers scale to set the opening pressure may result in an opening pressure which differs above or below that indicated on the scale by several centimetres of water. If an accurate setting is essential, then an external pressure transducer would be required to achieve this. We have, however, shown that work performed on the two devices differs little in most cases, and any such

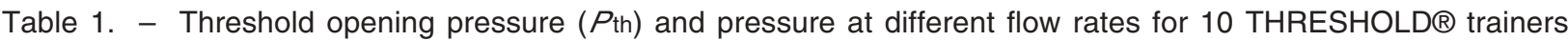

\begin{tabular}{|c|c|c|c|c|c|c|c|c|c|c|c|}
\hline \multirow{3}{*}{$\frac{\text { Set pressure }}{10 \mathrm{cmH}_{2} \mathrm{O}}$} & \multicolumn{11}{|c|}{ Pressure $\mathrm{cmH}_{2} \mathrm{O}$} \\
\hline & \multicolumn{2}{|c|}{$P$ th } & \multicolumn{2}{|c|}{ at $20 \mathrm{~L} \cdot \mathrm{min}^{-1-}$} & \multicolumn{2}{|c|}{$40 \mathrm{~L} \cdot \mathrm{min}^{-1}$} & $60 \mathrm{~L} \cdot \mathrm{min}^{-1}$ & \multicolumn{2}{|c|}{$80 \mathrm{~L} \cdot \mathrm{min}^{-1}$} & \multicolumn{2}{|c|}{$100 \mathrm{~L} \cdot \mathrm{min}^{-1}$} \\
\hline & 8.2 & $(0.8)$ & 9.2 & $(1.0)$ & 10.0 & $(0.6)$ & $10.1 \quad(0.7)$ & 10.2 & $(0.6)$ & 10.4 & $(0.7)$ \\
\hline $20 \mathrm{cmH}_{2} \mathrm{O}$ & 16.9 & $(1.2)$ & 18.6 & $(0.7)$ & 19.7 & $(0.8)$ & $20.3 \quad(0.8)$ & 20.5 & $(1.0)$ & 20.8 & $(1.0)$ \\
\hline $30 \mathrm{cmH}_{2} \mathrm{O}$ & 24.8 & $(1.8)$ & 28.7 & $(1.2)$ & 30.3 & $(1.2)$ & $30.9 \quad(1.1)$ & 31.3 & (1.1) & 31.7 & $(0.8)$ \\
\hline $40 \mathrm{cmH}_{2} \mathrm{O}$ & 37.6 & $(2.0)$ & 39.6 & (1.4) & 40.4 & $(1.3)$ & $41.6 \quad(1.1)$ & 42.2 & (1.1) & 42.6 & $(0.8)$ \\
\hline
\end{tabular}

Values are presented as mean, and SD in parenthesis. 
differences are unlikely to be significant in clinical practice.

The THRESHOLD® device is inexpensive, costing $£ 11.50$ (about 23 US\$). Our weighted plunger system cost several hundred pounds to develop and build and would not be a practical option for inspiratory muscle training on a large scale. In a clinical setting, the THRESHOLD ${ }^{\circledR}$ trainer is adequate for inspiratory muscle training in most patients as it is simple to use and of a consistent quality.

\section{References}

1. Morrison NJ, Richardson J, Dunn L, Pardy R. Respiratory muscle performance in normal elderly subjects and patients with COPD. Chest 1989; 95: 90-91.

2. Mancini DM, Henson D, La Manca J, Levine S. Evidence of reduced respiratory muscle endurance in patients with heart failure. J Am Coll Cardiol 1994; 24 : 972-981.

3. Gosselink R, Decramer M. Inspiratory muscle training: where are we? Eur Respir J 1994; 7: 2103-2105.

4. Nickerson B, Keens T. Measuring ventilatory muscle endurance in humans as sustainable inspiratory pressure.
J Appl Physiol: Respirat Environ Exercise Physiol 1982; 52: 768-772.

5. Freedman S. Sustained maximum voluntary ventilation. Respir Physiol 1970; 8: 230-244.

6. Bardsley PA, Bentley S, Hall HS, Singh SJ, Evans DH, Morgan MDL. Measurement of inspiratory muscle performance with incremental threshold loading: a comparison of two techniques. Thorax 1993; 48: 354-359.

7. Eastwood PR, Hillman DR. A threshold loading device for testing of inspiratory muscle performance. Eur Respir $J$ 1995; 8: 463-466.

8. Ramonatxo M, Boulard P, Prefaut C. Validation of a noninvasive tension-time index of inspiratory muscles. J Appl Physiol 1995; 78: 646-653.

9. McElvaney G, Fairburn MS, Wilcox PG, Pardy RL. Comparison of two minute incremental threshold loading and maximal loading as measures of respiratory muscle endurance. Chest 1989; 96: 557-563.

10. Eastwood PR, Hillman DR, Finucane KE. Ventilatory responses to inspiratory threshold loading and role of muscle fatigue in task failure. $J$ Appl Physiol 1994; 76 : 185-195.

11. Lisboa C, Munoz V, Beroiza T, Leiva A, Cruz E. Inspiratory muscle training in chronic airflow limitation: comparison of two different training loads with a threshold device. Eur Respir J 1994; 7: 1266-1274. 